\title{
Chiropractic Rehabilitation of a Scoliosis Family: Results from a 9-Year Follow-Up
}

\author{
Mark W. Morningstar ${ }^{1 *}$, Aatif Siddiqui ${ }^{2}$, Clayton Stitzel ${ }^{3}$, Brian Dovorany ${ }^{4}$ \\ ${ }^{1}$ Natural Wellness \& Pain Relief Center, Grand Blanc, MI, USA \\ ${ }^{2}$ Esprit Wellness Chiropractic \& Physical Therapy, New York, NY, USA \\ ${ }^{3}$ Lancaster Spinal Health Center, Lititz, PA, USA \\ ${ }^{4}$ Posture \& Spine Care Center, Green Bay, WI, USA \\ Email:*drmorningstar@nwprc.com
}

How to cite this paper: Morningstar M.W., Siddiqui, A., Stitzel, C. and Dovorany, B. (2017) Chiropractic Rehabilitation of a Scoliosis Family: Results from a 9-Year Follow-Up. Open Journal of Therapy and Rehabilitation, 5, 29-35.

https://doi.org/10.4236/ojtr.2017.51003

Received: November 10, 2016

Accepted: January 22, 2017

Published: January 25, 2017

Copyright (C) 2017 by authors and Scientific Research Publishing Inc. This work is licensed under the Creative Commons Attribution International License (CC BY 4.0).

http://creativecommons.org/licenses/by/4.0/

\begin{abstract}
Scoliosis bracing is typically prescribed when the curvature reaches to between $30^{\circ}-50^{\circ}$. Although there has been a vast amount of bracing literature published, the results remain equivocal. Many patients face issues of compliance, comfort, and decreased self-esteem due to social stigmas with bracing. This has caused many patients to seek non-bracing options. Although these treatments are plausible, they lack the research background that bracing has. Therefore, many physicians are reluctant to prescribe exercise-based rehabilitation for their scoliosis patients. This study reports on 3 patients who sought non-bracing, exercise-based chiropractic rehabilitation for their scoliosis. Their results before, after, and at long term follow up are included.
\end{abstract}

\section{Keywords}

Chiropractic, Scoliosis, Spine, Rehabilitation

\section{Introduction}

In the United States, the three-dimensional spinal deformity known as scoliosis is typically treated using surgical intervention when the degree of curvature exceeds $50^{\circ}$ [1]. When the scoliosis is between $25^{\circ}-50^{\circ}$, rigid or dynamic spinal orthosis is typically recommended as a way to prevent curvature progression [1]. While these treatments have a long history of publication, exercise-based therapies have offered far less published data [2]. Of these, chiropractic treatment of scoliosis has only been published in a handful of case reports or series [3].

In a recent article by Weiss [4], it was recommended that all scoliosis treatment articles that evaluate various methods contain some essential key points, including a minimum of 5 -year follow-up on adult patients, a minimum of two- 
year follow-up on adolescent patients after they've reached skeletal maturity, and a calculated incidence of progression of at least $40 \%$ [4]. According to his literature review, no exercise-based physical therapy has been published to date that incorporate these criteria [4], nor has any paper outlining a chiropractic method [3].

This case series reports the results of 3 females, a mother and her 2 daughters, following a chiropractic rehabilitation treatment intervention. This family was selected due to the fact that they all participated in the same exercise-based scoliosis treatment, and each had a different scoliosis curve pattern. All of the patients began treatment as a result of pain caused by their respective scoliosis. At the time of initial presentation to the chiropractic clinic, the scoliosis in each case had already reached or surpassed the typical surgical threshold. However, the mother elected to avoid surgery for herself and for her daughters. The objective of this paper is to outline the results of this family, all with adolescent idiopathic scoliosis, who have been treated and then followed for nine years. This paper reports their changes in radiographic, pain, and daily function parameters obtained over this time period. All 3 patients gave their written permission to use their non-identifying outcome and demographic data.

\section{Case Reports}

\subsection{Mother}

A 51-year-old female mother of two presented to a chiropractic clinic for treatment of middle back, lower back, and right shoulder pain. Her back pain was rated as a $6 / 10$ on a numeric pain rating scale for both regions, and the shoulder pain was ranked as a $4 / 10$. All pain areas were painful at least $75 \%$ of the day, and made worse by postural stasis. Lying flat on her back and swimming helped to reduce the pain, but not eliminate it. The middle back pain was located medial and inferior to the right medial scapular border. The shoulder pain was located across the superior aspect of the scapula along the spine of the scapula. Her low back pain was located over her right sacroiliac joint and lumbosacral joint. The patient reported that she had had this pain for most of her adult life episodically. However, it had become more consistent and had increased severity over the previous 5 - 7 years. Other treatment options sought by the patient were physical therapy, including massage, ultrasound, electric stimulation, and stretching for a total of 24 sessions in 8 weeks. No relief was obtained as a result of this treatment. She was also given an option for sacroiliac steroid injections for pain management, which she refused.

Her initial physical assessment in the chiropractic clinic included radiographic, postural, and functional measures. The radiographic measurement included the Cobb angle to assess the scoliosis. In the mother's case, her Cobb angle measured $47^{\circ}$ (right thoracic). At baseline she completed a quadruple numeric pain rating scale (QVAS) [5] and a functional rating index (FRI) [6]. These scales provide information on the patient's pain and activities of daily living. Her initial scores were $47 \%$ and $55 \%$, respectively. 


\subsection{Daughter \#1}

The 16-year-old daughter presented to the clinic with a 3-year history of thoracolumbar pain and upper thoracic pain. Her thoracolumbar pain ranked as a $7 / 10$ while her upper thoracic painranked as a $4 / 10$. Her pain was present approximately $50 \%$ of the day. Sitting at school and driving in her car increased her pain, while walking, lying flat, and over the counter NSAIDS helped the pain. Her upper thoracic pain was located in the trapezius bilaterally, with the right side reported as slightly worse and more frequent than the left. The thoracolumbar pain beganat approximately T10 - T12 and radiated laterally on both sides. The pain was described as achy and constricting. She had previously tried chiropractic manipulation with two different chiropractors, receiving one or two treatments weekly between the two of them for approximately five months. She also recalled receiving 8 - 10 full-body massages in the previous three years. She related that these treatments helped her pain temporarily, from hours to days, but nothing consistent or sustained. Her radiographic measurements were as follows: right thoracic scoliosis of $63^{\circ}$ with an apex of T10. The ATR measured at $14^{\circ}$, her baseline QVAS score was 63 , and her initial FRI was $68 \%$.

\subsection{Daughter \#2}

The 14-year-old daughter presented to the clinic with a new onset of middle thoracic pain. The pain began insidiously approximately one month prior. She rated the pain as a $7 / 10$, and was present nearly $100 \%$ of the waking day. Sitting at her desk at school, walking, and jogging all increased the pain. Rest and NSAIDS improved the pain, but only reduced it to about a $3 / 10$ according to the patient. The pain was located at the thoracolumbar junction slightly right of the spine, approximately where the transitional region was between the lumbar and thoraciccurvatures on radiograph. She had not sought any treatment elsewhere. She primarily sought care at my office first because she came with her mother and sister for their initial visits, and chose to have one herself. On radiographic examination, she displayed a right thoracic/left lumbar double major scoliosis, with the thoracic curvature measuring $35^{\circ}$ and the lumbar curvature $41^{\circ}$. Her initial QVAS and FRI scores were $27 \%$ and $25 \%$, respectively, and her sitting ATR measured $9^{\circ}$.

\subsection{Treatment}

All three patients participated in a chiropractic rehabilitation program consisting of scoliosis and postural specific exercises. Modalities included external head and body weighting, positional spinal traction, fulcrum exercises, rotary torso exercises, vibration therapy, and spinal manipulation. Figure 1 illustrates the various modalities performed by these patients.

The initial course of treatment consisted of once weekly clinic treatments and required home care exercises. The weekly treatments lasted for six months, after which time they were followed with twice yearly, or as needed for pain. Beyond the initial six-month treatment regimen, the Mother presented to the office for a 
total of 37 visits over the subsequent nine years and one month, while Daughter \#1 and Daughter \#2 came in 26 and 17 times, respectively over the same time period.

\subsection{Results}

During subsequent follow-up visits, postural assessment and the angle of trunk rotation (ATR), were collected at least twice yearly. Radiographic cobb angle measurements were collected during years 1, 5, 7, and 9. At the time of re-evaluation in year 9 , the Mother had a Cobb angle of $34^{\circ}$, with self-reported QVAS and FRI scores of 17 and 33, respectively. Daughter \#1 showed a Cobb angle of $54^{\circ}$, QVAS of 33, and FRI of 35. Finally, Daughter \#2 had the following results: Cobb angle of $31^{\circ} \mathrm{T} / 33^{\circ} \mathrm{L}, \mathrm{QVAS}$ of 13 , and FRI of 13 . Figure 2 summarizes the Cobb angle results for all three patients at baseline, 1 year, 5 years, 7 years, and 9 years. Figure 3 shows results for the QVAS at baseline, 1 year, and 9 years. Figure 4 shows these same data points for the FRI questionnaire.
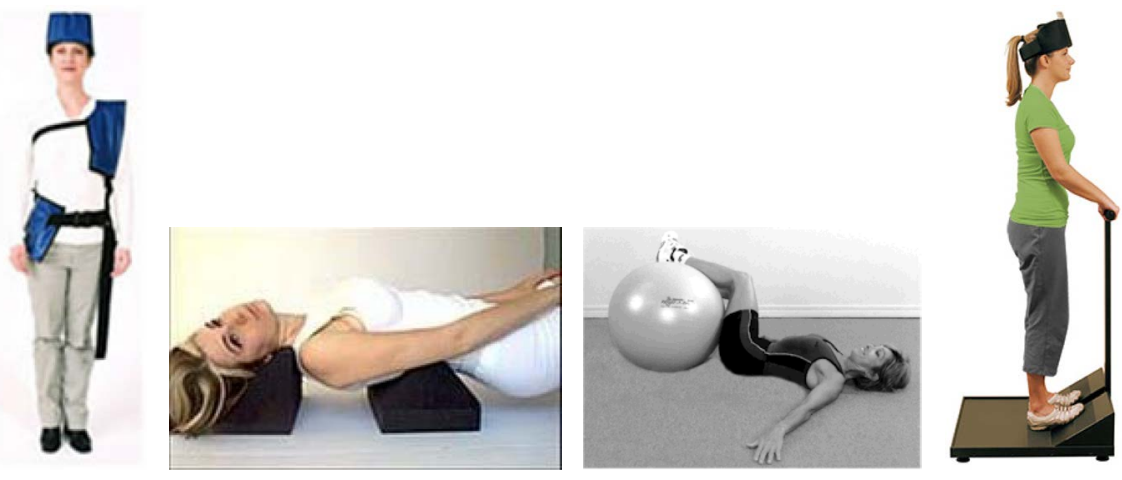

Figure 1. This figure illustrates the therapies used by these patients over the course of their respective treatment. These include, from left to right, Pettibon Weighting System, fulcrum exercises, rotary torso exercises, and vibration therapy on a vibration platform.

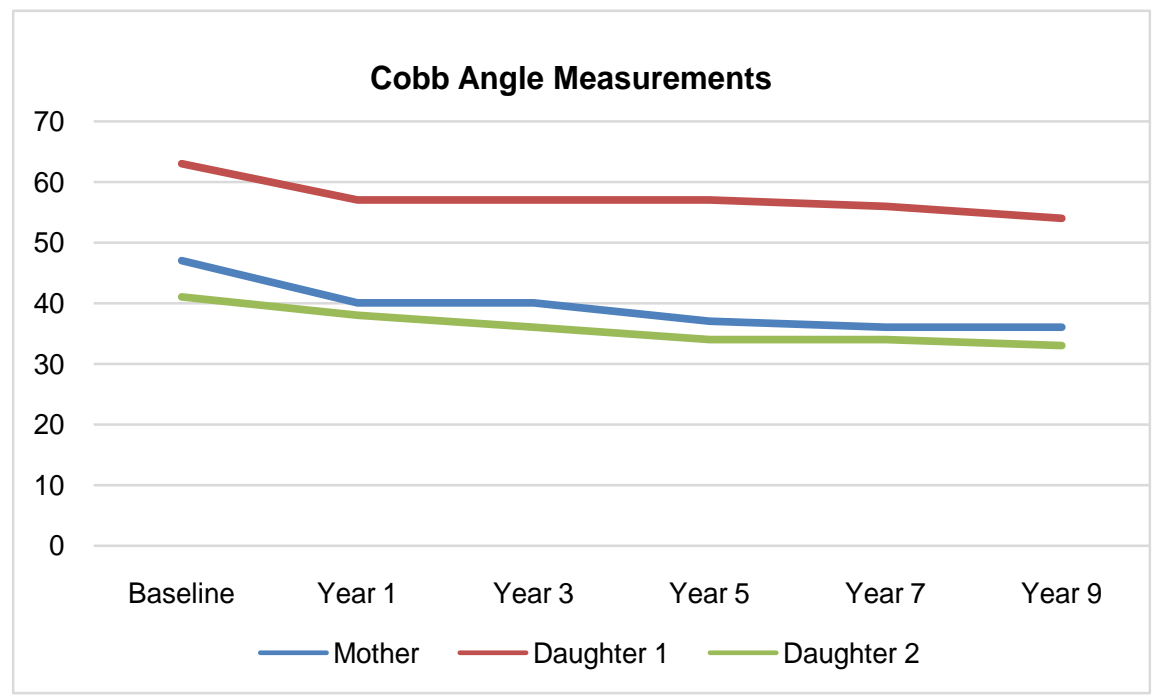

Figure 2. This figure summarizes the Cobb angle measurements recorded for each patient. 


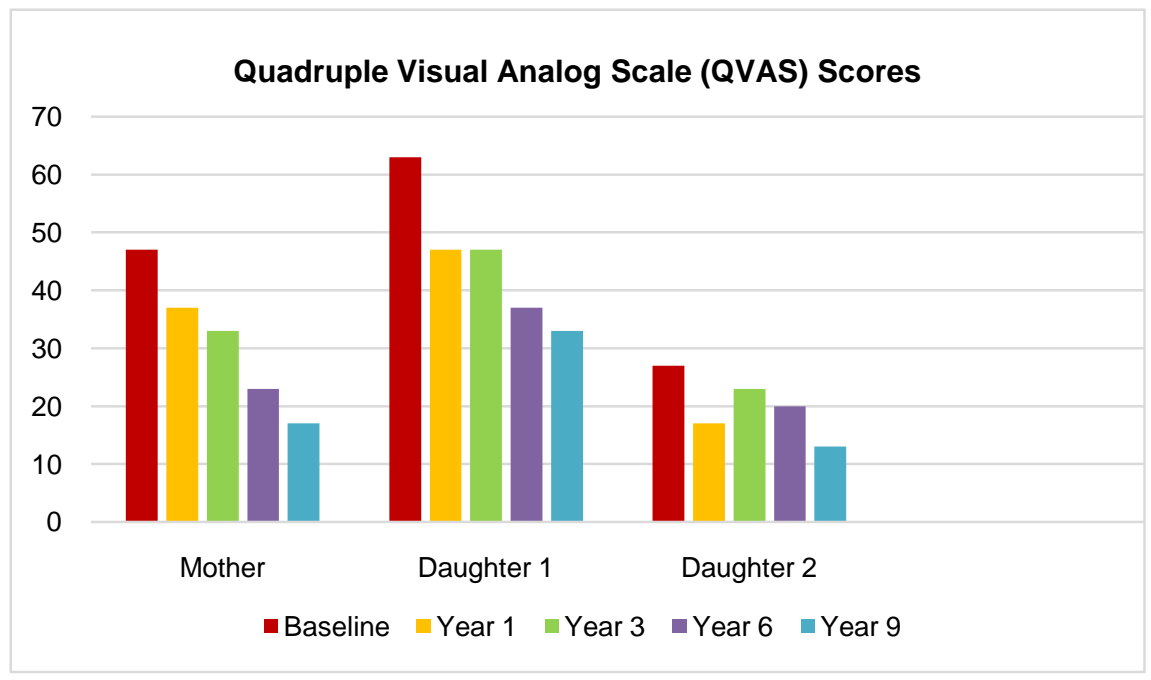

Figure 3. An illustration of the QVAS outcomes at baseline and Years 1, 3, 6 and 9.

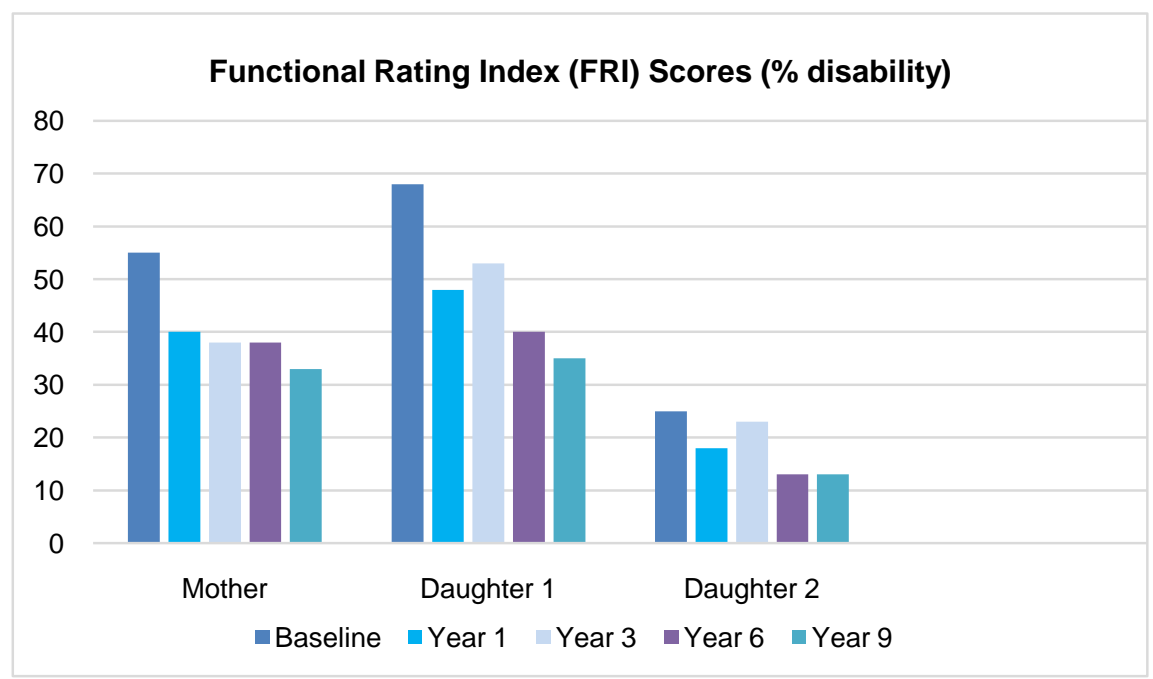

Figure 4. Functional rating index outcomes for all patients.

\section{Discussion}

In cases of progressive adolescent idiopathic scoliosis, the curvatures continue to increase $1^{\circ}-1.5^{\circ}$ yearly in adulthood at a nearly linear rate [7]. It would appear that all 3 patients have altered the natural course of their curvatures. Whether or not this was due to the treatment remains unknown due to the study design. Based on the natural history of scoliosis [7], it is unlikely that the observed improvements in these patients were attributed to natural history, but rather due to the prescribed treatment.

This case report is the first to evaluate a chiropractic treatment method for scoliosis using the recommended reporting guidelines by Weiss [4]. All 3 patients had their initial diagnosis during adolescence. At the time of presentation to my office, all three patients had curvatures that had previously progressed to a point where they met or exceeded surgical threshold [8]. Finally, the length of follow-up reported for these patients exceeds the five year recommendation for 
adult patients [4].

\section{Limitations}

There are some limitations that should be discussed. Because of the emphasis on home care for the duration of the follow-up period, it would have been helpful to have had the patients complete an exercise diary to record their respective levels of compliance with home care. This would have likely have a direct impact on the magnitude of the patient's results. The multimodal nature of the treatment each of the patients received does not allow us to identify which therapy or therapies were the most beneficial in achieving curve correction. However, since these therapies are not clinically practiced in isolation, this case series represents a practice pattern that might be more indicative of the typical rehabilitation practice. This study is also not immune to selection bias, as are all retrospective study designs. This prevents us from extrapolating these results to other cases. However, the purpose of this study was to document the long-term results of 3 relatives who all had scoliosis, regardless of the outcomes.

\section{Conclusion}

A mother and her 2 daughters reported to a private medical clinic for treatment of idiopathic scoliosis. All 3 patients had differing curve patterns. Following the completion of a prescribed chiropractic rehabilitation treatment, and after 9 years of intermittent follow-up, all 3 patients demonstrated a correction of at least $6^{\circ}$ in their respective scoliosis. They also demonstrated improvements in their self-rated pain scores and activities of daily living. Future investigations into chiropractic rehabilitation of scoliosis should include prospective study designs and control groups when possible.

\section{Conflict of Interest}

The authors declare that there are no conflicts of interest.

\section{References}

[1] Scoliosis Research Society. www.srs.org

[2] Hawes, M.C. (2003) The Use of Exercises in the Treatment of Scoliosis: An Evidence-Based Critical Review of the Literature. Pediatric Rehabilitation, 6, 171-182. https://doi.org/10.1080/0963828032000159202

[3] Romano, M. and Negrini, S. (2008) Manual Therapy as a Conservative Treatment for Adolescent Idiopathic Scoliosis: A Systematic Review. Scoliosis, 3, 2. https://doi.org/10.1186/1748-7161-3-2

[4] Weiss, H.R. (2012) Physical Therapy Intervention Studies on Idiopathic Scoliosis-Review with The focus on Inclusion Criteria. Scoliosis, 7, 4 https://doi.org/10.1186/1748-7161-7-4

[5] Jensen, M.P. and Karoly, P. (1993) Self Report Scales and Procedures for Assessing Pain in Adults. In: Turk, D.C. and Melzack, R., Eds., Handbook of Pain Assessment, Guildford Press, New York, 15-34.

[6] Feise, R.J. and Menke, J.M. (2001) Functional Rating Index: A New Valid and Relia- 
ble Instrument to Measure the Magnitude of Clinical Changes in Spinal Conditions. Spine, 26, 78-87. https://doi.org/10.1097/00007632-200101010-00015

[7] Marty-Poumarat, C., Scattin, L., Marpeau, M., Garreau de Loubresse, C. and Aegerter, P. (2007) Natural History of Progressive Adult Scoliosis. Spine, 32, 1227-1234. https://doi.org/10.1097/01.brs.0000263328.89135.a6

[8] Weinstein, S.L., Dolan, L.A., Spratt, K.F., Peterson, K.K., Spoonamore, M.J. and Ponseti, I.V. (2003) Health and Function of Patients with Untreated Idiopathic Scoliosis: A 50-Year Natural History Study. JAMA, 289, 559-567.

https://doi.org/10.1001/jama.289.5.559

\section{Scientific Research Publishing}

Submit or recommend next manuscript to SCIRP and we will provide best service for you:

Accepting pre-submission inquiries through Email, Facebook, LinkedIn, Twitter, etc. A wide selection of journals (inclusive of 9 subjects, more than 200 journals) Providing 24-hour high-quality service User-friendly online submission system Fair and swift peer-review system Efficient typesetting and proofreading procedure Display of the result of downloads and visits, as well as the number of cited articles Maximum dissemination of your research work

Submit your manuscript at: http://papersubmission.scirp.org/ Or contact ojtr@scirp.org 